(2014). Classroom Social Signal Analysis. Journal of Learning Analytics, 1 (3), 176-178.

\title{
Classroom Social Signal Analysis
}

\author{
Mirko Raca and Pierre Dillenbourg \\ CHILI Laboratory \\ École polytechnique fédérale de Lausanne, Switzerland \\ mirko.raca@epfl.ch
}

\begin{abstract}
We present our efforts towards building an observational system for measuring classroom activity. The goal is to explore visual cues which can be acquired with a system of video cameras and automatically processed to enrich the teacher's perception of the audience. The paper will give a brief overview of our methodology, explored features, and current findings.
\end{abstract}

KEYWORDS: Video analysis, computer vision, tracking, intrusiveness, body motion, head pose, classroom, students' synchronization, orchestration

\section{INTRODUCTION}

As much as humans developed as social animals, our perceptional and cognitive abilities still limit the comprehension of our interlocutor(s). While we are capable of interpreting unspoken signals in a one-toone conversation, the task becomes much more challenging when faced with an audience of thirty or more students, with minimal interaction. We aim to enrich the classroom ecosystem with information about the state of the audience's attention, presented to the teacher to raise the awareness of how the students are receiving the lecture. The research is rooted in concepts of observational data gathering, meaning that our main source of information is not based on probing the information from the students (e.g., using an application to state their attention), but rather on analyzing the cues we can gather from body language to deduce the state of the audience.

The data is captured with a system of cameras positioned around the blackboard of the classroom. The video material is processed with Computer Vision (CV) techniques such as motion detection, head detection, and head orientation estimation. Our current efforts are aimed at determining meaningful patterns of behaviour and finding the most salient features. The second part of the research aims to model student behaviour and finally to discuss how to present the information back to the teacher in order to encourage reflective practice in teaching.

Our efforts build on the concepts of classroom orchestration (Dillenbourg \& Jermann, 2010) and teachercentric structure of the classroom. The main difference from the current approaches, such as the usage of clickers (Caldwell, 2007), is the principle of unobtrusiveness (Webb, Campbell, Schwartz, \& Sechrest, 1999), which constrains our interventions so that they will enrich the teaching process without imposing a specific format of the class or adding another feedback tool to the classroom. 


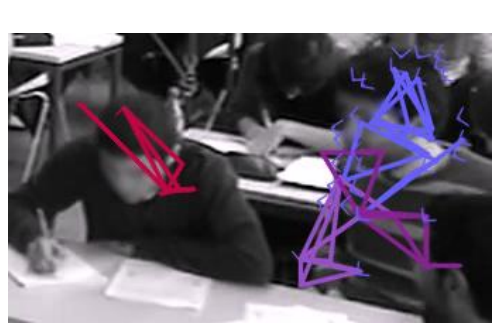

a)

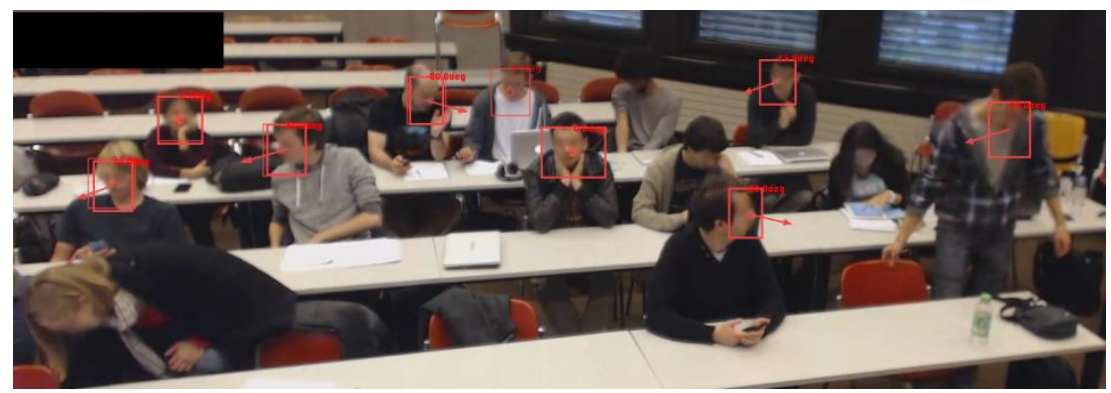

b)

Figure 1: a) Motion vectors visualized on top of the students. Individual vectors are grouped into motion paths depicted as lines of different colours. b) Head detections and estimated gaze directions for a group of students in the classroom.

\section{METHODOLOGY}

We conducted a series of experiments for capturing student behaviour during class. Given the complexity of the classroom ecosystem, we conducted a holistic analysis of the classroom (Raca \& Dillenbourg, 2014), capturing many aspects of classroom life including:

- Videos of student behaviour from which we extracted motion intensity and head orientation for each student over time (shown in Figure $1 \mathrm{a}$ and $1 \mathrm{~b}$ ).

- Video of teacher actions/lecture slides: we applied tracking algorithms to find the position of the teacher over time and we annotated events during the lecture (slide changes, question/answer periods).

- Questionnaires: we distributed questionnaires on which the students reported their level of attention, perception of overall classroom attention, material importance, and teacher energy.

- Interviews: a smaller subset of students participated in the interview sessions in order to evaluate student perceptions of the system and validity of the questionnaires.

- Eye-tracker: the teachers wore a portable eye-tracker during the lectures, from which we extracted the gaze patterns of the teachers.

\section{RESULTS}

Our initial set of experiments on motion showed no direct connection between the motion of the students and their attention levels (reported in the questionnaires), but gave grounds for the definition of the concept of "motion lag" (Raca, Tormey, \& Dillenbourg, 2014) — the idea that high-attention students will more likely be synchronized in their actions. From this, we hypothesize that the synchronization influence comes from the external environment, and that the dominant signal in a good classroom will be the teacher. We also observed that the spatial arrangement is also manifested in the 
(2014). Classroom Social Signal Analysis. Journal of Learning Analytics, 1 (3), 176-178.

results, neighbouring students being more likely to synchronize and that the intensity of the motion decreases with the distance from the teacher (Raca, Tormey, \& Dillenbourg, 2013).

Our next steps are directed towards refining our head-pose estimations (Raca \& Dillenbourg, 2014) and analyzing the observations received from this data stream before merging them into a unified model with earlier findings.

\section{REFERENCES}

Caldwell, J. E. (2007). Clickers in the large classroom: Current research and best-practice tips. CBE-Life Sciences Education, 6(1), 9-20.

Dillenbourg, P., \& Jermann, P. (2010). Technology for classroom orchestration. In M.S. Khine \& I.M. Saleh (Eds.), New science of learning (pp. 525-552). New York: Springer.

Raca, M., \& Dillenbourg, P. (2014, November). Holistic analysis of the classroom. In Proceedings of the 2014 workshop on Multimodal Learning Analytics Workshop and Grand Challenge (pp. 13-20). New York: ACM.

Raca, M., Tormey, R., \& Dillenbourg, P. (2013). Student motion and its potential as a classroom performance metric. In 3rd International Workshop on Teaching Analytics (IWTA). Aachen, CEUR.

Raca, M., Tormey, R., \& Dillenbourg, P. (2014, March). Sleepers' lag-study on motion and attention. Proceedings of the 4th International Conference on Learning Analytics and Knowledge (pp. 3643). New York: ACM.

Webb, E. J., Campbell, D. T., Schwartz, R. D., \& Sechrest, L. (1999). Unobtrusive measures (Vol. 2). Thousand Oaks: Sage Publications. 